\title{
Pineal parenchymal tumor of intermediate differenciation
}

INSERM

\section{Source}

INSERM. (1999). Orphanet: an online rare disease and orphan drug data base. $\underline{\text { Pineal }}$ parenchymal tumor of intermediate differenciation. ORPHA:251919

Pineal parenchymal tumor of intermediate differentiation (PPTID) describes a rare type of pineal parenchymal tumor (PPT) of intermediate-grade malignancy manifesting with visual disturbances, headaches, loss of coordination and balance, nausea and vomiting due to obstructive hydrocephalus, and that is classified as either grade II PPTID or grade III PPTID according to the degree of neuronal differentiation and mitotic activity. 